\title{
Pós-fácil - Filosofia Floresta para uma Escola de Arte
}

\author{
Post-Easy - \\ Forest Philosophy for an Art School
}

\author{
Post-fácil - \\ Filosofía Floresta para una escuela de arte
}

Luiz Guilherme Vergara *

http://dx.doi.org/10.22409/poiesis.2033.293-320

RESUMO: Este ensaio de uma filosofia floresta propõe como prospecção a reconfiguração de valores que realimentam o fenômeno humano tão ameaçado pela globalização capitalista em jogo. O que se percebe, na mesma medida deste desmonte do bem comum da esfera pública, é a emergência de linhas de forças intuitivas agindo como resistências pragmáticas e ressonâncias ancestrais que compõem uma rede de práticas coletivas decoloniais de desobediências e estados de "descoberta-invenção", constituindo uma gênese de processos de afetividades e conectividades experimentais. Desde "Devolver a Terra a Terra" de Hélio Oiticica à "alegria" em Graça Aranha e Oswald de Andrade, tem-se a floresta como horizonte de "conexões improváveis" livres. A partir de Guilherme Vaz, a intuição, comunhão, alegria e dádiva são tomadas como ecos da antropofagia do lugar escoladevir floresta da arte como "acontecimento da conectividade que dá sentido à existência, retornando ao mundo um novo mundo quando está conectado."

PALAVRAS-CHAVE: escola de arte; antropofagia; conexões improváveis; floresta

\footnotetext{
* Luiz Guilherme Vergara é professor associado do Departamento de Arte e do Programa de Pós-Graduação em Estudos Contemporâneos das Artes da UFF. É cofundador do Instituto MESA e coeditor da Revista MESA. E-mail: luizguivergara@gmail.com
} 
ABSTRACT: This essay proposes and explores what can be called a forest philosophy - a prospective reconfiguration of values that nurture the human experience so threatened by capitalist globalization. At the same time, amidst the dismantling of the common good of the public sphere, we can perceive the emergence of lines of flight and intuitive forces acting as pragmatic resistances and ancestral resonances that, in turn, compose a network of decolonial collective practices of disobedience and states of "invention-invention," constituting a genesis of affective processes and experimental connectivity. In works such as the artist Hélio Oiticica's "Returning the Earth to Earth" or the "joy" as noted in the writers Graça Aranha and Oswald de Andrade, the forest can be seen as a horizon of free "unlikely connections." Drawing on these references and especially on the inspirational work of musician and artist Guilherme Vaz, the article explores intuition, communion, joy, and gift as key concepts embracing anthropophagic echoes of a school as a place of forest-becoming where the forest of art emerges as "an event of connectivity that gives meaning to existence, returning to the world a new world when connected."

KEYWORDS: art school; anthropophagy; unlikely connections; forest

RESUMEN: Este ensayo de una filosofía "floresta" propone como prospección de la reconfiguración de valores que alimentan el fenómeno humano tan amenazado por la globalización capitalista en juego. Lo que se percibe, en la misma medida de este desmantelamiento del bien común de la esfera pública, es el surgimiento de líneas de fuerzas intuitivas que actúan como resistencias pragmáticas y resonancias ancestrales que componen una red de prácticas colectivas decoloniales de desobediencia y estados de "descubrimiento-invención", constituyendo una génesis de procesos de afectividad y conectividades experimentales. Desde "Devolviendo la Tierra a la Tierra" de Helio Oiticica a la "alegría" en Graça Aranha y Oswald de Andrade, uno tiene al bosque como un horizonte de "conexiones poco probables" libres. Desde Guilherme Vaz, la intuición, la comunión, la alegría y el don se toman como ecos de la antropofagia de la escuela, lugar del bosque del arte, como "un evento de conectividad que da sentido a la existencia, devolviendo al mundo un mundo nuevo cuando está conectado".

PALABRAS CLAVE: infinito; regalo; el silencio; conexión improbable; comunion

Como citar: VERGARA, Luiz Guilherme. Pós-fácil - Filosofia Floresta para uma Escola de Arte. Poiésis, Niterói, v. 20, n. 33, p. 293-320, jan./jun. 2019. doi: http://dx.doi.org/10.22409/poiesis.2033.293-320

Poiésis, Niterói, v. 20, n. 33, jan./jun. 2019. 


\section{Pós-fácil - \\ Filosofia Floresta para uma Escola de Arte}

Não existe arte sem ressonância. A intuição é parte de um estado paradoxal de
comunhão com um contexto que junta coisas aparentemente improváveis de se
conectarem.

O’’ estado de comunhão é uma dádiva ou dom de uma metafísica da arte. Unir signos díspares.

A experiência do estado de comunhão paradoxalmente dá sentido à existência, ao que ainda não tem lugar na consciência do mundo.

0 lugar da arte é o do acontecimento da conectividade que dá sentido à existência, retornando ao mundo um novo mundo quando está conectado.

-- Guilherme Vaz ${ }^{1}$

As especulações filosóficas de Guilherme Vaz formam vários entrecruzamentos conceituais para essa abordagem entre escola de arte e devir floresta, como parte de uma escuta centrada em sua experiência de escuta e de fala de múltiplas vozes atravessando várias fronteiras do Brasil profundo. Como uma concha acústica de ressonâncias e ecos, 
emergem afirmações da mais pura intuição sobre o "lugar da arte é o do acontecimento da conectividade que dá sentido à existência, retornando ao mundo um novo mundo quando está conectado." Para tanto, Vaz traz o pensamento e a sensibilidade floresta para uma percepção fenomenológica da "experiência do estado de comunhão e, paradoxalmente, dá sentido à existência ao que ainda não tem lugar na consciência do mundo." Esse "estado de comunhão é uma dádiva ou dom de uma metafísica da arte. Unir signos díspares." Nesta longa conversa com Vaz (que aqui publicamos), ele prefere chamar de Filosofia da Arte onde realmente pode lembrar de várias conexões improváveis que marcaram sua vida da música à experiência atonal, daí para a arte conceitual, vídeo performance e, ao final, o próprio convívio na floresta com os índios. Como introdução ou inspiração para esta escola de arte, tomam-se as enunciações intuitivas livres de Guilherme Vaz como ponto de partida para uma filosofia floresta entre emaranhamentos e outramentos do pensamento livre - "sobreviver ensinando as conquistas de minha consciência das áreas do inconsciente." O que leva o artista a uma prática e processos do fazer e saber, ensinar e aprender como conquistas da consciência em áreas não ainda consciente. $\mathrm{A}$ floresta estaria então para o consciente como fronteiras do que somente pela intuição palpável da experiência é conquistado - o espírito livre; o pensar, sentir e agir livre.

A escola floresta é então da conquista da consciência do pensamento livre que se faz pela conectividade, a interpenetrabilidade multissensorial com o mundo ao redor. É desta escola que Guilherme Vaz provoca conexões improváveis, tais como o radicalismo de poder cruzar o samba do Noel Rosa com uma obra que se reduz a uma frase - mantra de experiência multidirecional - "ande para qualquer lugar", qualquer direção. Mas também é tão contemporânea como uma proposta Fluxus ou mesmo um exercício de meditação Zen. Nela também se dá um total "des-criar", des-forma estética onde o completo esvaziamento se torna linha de força e campo de potencialidades de experiências do que Mario Pedrosa abordava no "lance final" das especulações estéticas como "espessura do presente". É nesse andar para qualquer lugar, onde o lugar qualquer se torna potência.

Poiésis, Niterói, v. 20, n. 33, jan./jun. 2019. 


\section{Todos os campos sen soriais vão passando a ser, desde já, objetos também da pesquisa estética, para além do visual, do auditivo, to tátil, e, digamos, do olfativo. Pesquisa que não se proponha a desbravamentos dessa ordem, a quebrar os limites das “espessuras do presente, em qualquer campo, não terá caráter ou categoria de inovadora. ${ }^{2}$}

Várias camadas de sentidos hermenêuticos não ainda suficientemente estudados aproximam a escola de samba com a floresta da alegria cósmica enunciada como princípio para uma "Esthetica da Vida" por Graça Aranha (1921). Ou a história do Brasil refletida por enunciações anacrônicas expressas no manifesto antropofágico de Oswald de Andrade, assim como as ressonâncias mútuas entre arte, alegria e estratégias de resistência afrobrasileira são fundadoras da "escola de samba", aqui revisitadas a partir de um olhar estrangeiro de Jessica Gogan na conversa com Daniela Name e Felipe Ferreira. É destas brechas da memória porvir que várias incertezas foram sendo abertas, quem sabe como outra escola de conquistas do não ainda consciente. Deixa Falar inspira este diálogo entrecruzando diferentes sentidos de "escola" nas escolas de Samba. O quanto de escola se camufla nesta floresta do samba, mas também o quanto de escola de outramentos antropofágicos habitam os devires da floresta do samba? Este diálogo explora essas indagações próprias de uma estrangeira que não naturalizou a potência das florestas em escolas gaiolas. Por que "escola" de samba? Por que esta conjunção? De onde surgiu? Que fortes aproximações, ainda-não devidamente abordadas, aproximam o jogo poético de Oswald de Andrade no Manifesto Pau Brasil (1924), seu Manifesto Antropofágico de 1928 provocando o anacronismo critico entre "floresta" e "escola" e a inauguração da primeira Escola de Samba - Deixa Falar apenas três meses depois? De um desejo de subversão ou aceitação?

No entanto, em 2019, apesar de todo colapso democrático brasileiro, essa utopia antropofágica da floresta camuflada de escola de samba da Mangueira trouxe para a voz do povo, em seu enredo, uma história de ninar e de acordar gente grande. Daniela Name abre seu coração e encerra a questão: "Brasil, teu nome é Dandara... as mulheres negras desfilando e batendo no peito... O meu nome é Dandara!! Erraram na letra para tomar posse do país! Isso aqui sou eu!" 


\title{
Missão essencial da arte: inaugurar conexões improváveis
}

\section{- 0 mundo separa a arte junta (Vaz)}

\author{
[...] me fala das luzes \\ da mudança de textura \\ que só podemos perceber \\ depois \\ na duração não \\ a indústria da vaidade \\ construída sobre o que deveria \\ proteger o seu ori, seu chakra \\ debaixo do sol \\ -- Stephanie Borges $(2019)^{3}$
}

Justaponho esta citação da Daniela Name - "o meu nome é Dandara!" - ao poema da Stephanie Borges, cabe ressaltar, que me foi oferecido por um companheiro desconhecido casual de uma viagem de barca entre Rio e Niterói. Em pleno horário de rush, me chama a atenção um jovem que se senta ao meu lado e abre um livro de poesia, enquanto já estava trabalhando no laptop na revisão deste texto. Porque é tão raro encontrar alguém com livro de poesia em horário onde todos estão correndo para os seus escritórios, mergulhados em celulares - black mirrors -, rotinas apressadas da vida? Mais ainda porque era um jovem que, com uma simpatia espontânea, me falou que estava indo para o lançamento deste livro da amiga dele - Stephanie Borges. Este poema foi selecionado randomicamente a partir de minha solicitação a Cleiton Santos. Assim, incluo esses versos como atravessamentos da realidade na escola onde "em qualquer lugar, em qualquer direção, de qualquer maneira" (VAZ, 2018), a intuição, a comunhão e Dandara - dádiva -, formam emaranhamentos e outramentos para uma filosofia floresta das indeterminâncias.

Poiésis, Niterói, v. 20, n. 33, jan./jun. 2019. 
Da mesma forma, esta complexidade errante geopoética é também cosmopoética em seu devir de ressonâncias para uma escola de arte. Os versos de Stephanie, mesmo sem conhecê-la, ao invadiram tão bem, tão anacronicamente, quebram qualquer linearidade residual de uma filosofia que se quer pensar livre - floresta - aberto para a realidade brasileira. O que alerta Stephanie são sintomas e intuições dos dilemas da arte-escola na armadilha da "indústria da vaidade... construída sobre o que deveria... proteger o seu ori, seu chakra... debaixo do sol". As escolas-gaiolas e muitas das instituições culturais são igualmente conduzidas como "indústrias de vaidade" por uma pedagogia neoliberal que alimenta o glamour dos polimentos estéticos ainda muito colonizados. Ao mesmo tempo, Stephanie invade com uma conclamação acidental, um desvio que devolve a lembrança das origens da arte de talismã, proteção e encantamentos debaixo do sol.

A "indústria de vaidade" espelha também o "anacronismo de uma utopia" levantado por Mario Pedrosa (AMARAL, 1981, p. 310), como uma herança dos oportunismos políticos de mentalidades ainda presentes nos cenários dos desgovernos nacionais atuais e a nossa alarmante desigualdade social. Ainda que Pedrosa se referisse à Brasília, a arquitetura dos monumentos modernistas, a realidade brasileira, talvez ainda mais grave hoje, também tem diante de si o confronto anacrônico, talvez muito mais desmascarado, não menos assustador, entre "marchas utópicas" e os colapsos das instituições públicas da arte, da educação e da democracia no Brasil. Somente, como registram-se nos artigos aqui reunidos, por imaginários antropofágicos e pragmatismos descolonizadores unem-se escolas e devires florestas, gaiolas e asas (Rubem Alves), quando os exercícios experimentais da liberdade incorporam pragmatismos éticos, estéticos e pedagógicos de engajamentos em movimentos sociais, políticos e ambientais. A busca por uma filosofia floresta para uma escola de arte seria então de táticas, derivas, indeterminâncias que geram "conexões improváveis" de Guilherme Vaz a Nietzsche, de serpentes e águias, da atenção e escuta rastejante da ginga, capoeira geopoética ao voo cosmopoético das alegrias cósmicas de Graça Aranha.

Não se pode negar o colapso da vida e das instituições do asfalto, como expressa Suzana Queiroga. É do confronto com a crise atual que se revitaliza esta resistência antropofágica 
como pragmatismo ético nas vozes coletadas pela Mônica Hoff. Uma guinada ou subversão para uma pedagogia libertadora ou "contra-pedagógica" é apresentada como escrita encarnada na intensidade do agora dando forma de manifesto radical de emancipação, autonomia e denúncia. Somente a antropofagia e a floresta podem nos unir pelo "desaprender e incendiar" velhas formas desmascaradas como micro-fascismos no domínio de pedagogias do medo, do controle, das instituições, da violência, da ordem e do progresso. Como desformar, queimar pedagogias que regem as escolas neoliberais onde ensina-se a "crueldade civilizatória" do patriarcalismo, do racismo velado pelo individualismo competitivo? Mônica imprime um ritmo poético em sua (de)marcação e repetição como mantra - "isso é contrapedagogia", aqui presente como utopia antropofágica contemporânea. Assim, o "desaprender e incendiar" incorpora um estado de consciência emergencial, como o correr para a savana para Guilherme Vaz, para deslocamentos mútuos entre política, educação e arte que invocam práticas experimentais de pedagogias, curadorias, éticas e estéticas da libertação e da esperança. São devires florestas em ação para as escolas, museus, assim como formação de estratégias e táticas de agenciamentos de transformações sociais.

O sentido de diagnóstico e síntese poética de Oswald de Andrade expressando as origens anacrônicas brasileiras em seu poema Pau Brasil inspira diferentes atualizações para uma cultura de outramentos, onde o binário Escola-Floresta se transforme em reversibilidades causais para o século XXI. Uma vez que este manifesto composto por imaginários poéticos, ainda assim de intelectuais urbanos, articula diferentes abordagens mito e críticas indissociáveis da condição de colonizados-colonizadores. Como avançar do mito antropofágico do poeta da paulicéia desvairada para um pragmatismo poético e pedagógico contemporâneo? Tal como Mônica Hoff, Rafael Zacca é parte de uma outra geração de artistas, poetas, pesquisadores acadêmicos que se debruçam em pesquisas-intervençõesinvenções nas quais a atuação artística é também ativista de uma educação experimental. Reconhecem não apenas o resgate dos fios soltos da antropofagia deixados como futuros não concluídos (inacabados) das vanguardas dos anos 60, ou pela virada existencial e política de Paulo Freire, como prospecções imanentes de emaranhamentos incivilizatórios,

Poiésis, Niterói, v. 20, n. 33, jan./jun. 2019. 
decoloniais, de devires floresta das linhas de fugas contra a cultura neoliberal e repressiva contemporânea. Assim apresentado por Rafael Zacca em "O coletivo como floresta e a pedagogia da imanência." Zacca reconfigura o sentido de floresta para uma "comunidade transespecífica, definida mais pela categoria de convivência do que pela do comum." Ao mesmo tempo, faz uma aproximação com o pensar floresta através da filosofia de Paulo Freire - tirando da Pedagogia do oprimido, a categoria do inacabado, do incontornável. ${ }^{4}$ Mundo e ser humano são definidos pelo signo de seu inacabamento.

\section{Não por acaso se desenhou entre nós uma pedagogia "da imanência, cujo principal impulso foi dado pela filosofia de Paulo Freire. Que a sua filosofia se funde em nossa vocação para a floresta - que a escola e a floresta de Oswald encontrem em sua filosofia a sua face mais fecunda - ainda não foi suficientemente esclarecido. Pois há, na pedagogia e na concepção da humanidade em Freire, não apenas a constatação da existência como também da necessidade da diferença no processo do vir-a-ser de qualquer ser hu- mano.}

A potência ética pedagógica se dobra em poética da convivialidade das diferenças, da "maloka", como laboratórios de micro-utopias, dos devires de uma revolução floresta onde o existir é indissociável da necessidade de acolher, diferir por conectividades em polifonias imanentes de afetos alegres - geradores de potência de agir, de multiplicar subjetividades. As ações coletivas de Zacca fazem parte das antecipações poéticas e pedagógicas das escolas de Andrade e de Freire, onde o acontecer floresta está implícito a uma ecologia do compartilhamento e a uma ética viva da interdependência dos afetos.

Deste percurso imantado de pragmatismos utópicos e antropofágicos, apresenta-se a "Escola de Floresta" de Fábio Tremonte como parte deste movimento de resistência, autonomia e libertação. Uma "escola de artista" que propõe pensar e agir com arte, incorporado a uma educação como escultura-estrutura nômade de ressonâncias anarquistas do "descobrir, conhecer, ensinar e aprender a partir de outros possíveis saberes, sejam aqueles que utilizamos em nosso cotidiano, até saberes populares e ancestrais, passando pelos saberes ditos não-oficiais e presentes nos currículos oficiais. 
Coloca-se em questão não apenas a formação, mas a própria educação do artista, tal como Luiz Sérgio de Oliveira explora como parte de uma virada para a arte pública em seu sentido mais radical de escola de engajamento e posicionamento ético, estético e político. Pode-se considerar que tanto o artista está sendo também deslocado de seu lugar social como produtor de obras para apreciações e situações expositivas, como o educador já não mais pode se acomodar como transmissor de informações ou conhecimentos préestabelecidos por narrativas fixas. Ampliando as questões da arte pública, para ambos, em suas escolas e formação, entrelaçam-se papéis, artistas, ativistas, educadores e agentes de organização e transformação social. O que cabe também ampliar a educação do artista em "um processo de formação que o habilite a enfrentar essa nova realidade da arte". (OLIVEIRA, 2019) O que se coloca em jogo é o próprio instituir da convergência desses campos onde outras habilidades "extraordinárias" (VAZ, 2016), fazeres e saberes sejam geradores de dobras e desdobras de sentidos de existir e re-existir tanto do artista quanto do educador, tanto do museu quanto da escola.

O que se pode observar neste dossiê são linhas de fugas onde todas as escolas e universidades estão sendo deslocadas de suas zonas de conforto, pressionadas por abalos políticos e ontológicos de retrocessos sociais e ambientais ainda não avaliados. $\mathrm{O}$ agir por viradas e rupturas epistêmicas conduz também a uma condição experimental de desaprender, sair do centro para escutar o entorno, conforme Guilherme Vaz propõe em sua entrevista (aqui transcrita em sua íntegra). Um outro "aprender e incendiar" (Hoff) também se dá pela intuição, pelo esvaziamento do ego do artista que possa levar a escuta de outras vozes de devires floresta, a "comunhão e a dádiva", a "conexões improváveis", como convergência ecossistêmica entre criação e um novo protagonismo social da arte.

\footnotetext{
Não existe arte sem ressonância. A intuição é parte de um estado paradoxal de comunhão com um contexto que junta coisas aparentemente improváveis de se conectarem. 0 estado de comunhão é uma dádiva ou dom de uma metafísica da arte. Unir signos díspares. A experiência do estado de comunhão paradoxalmente dá sentido à existência, ao que ainda não tem lugar na consciência do mundo. (Vaz)
}

Poiésis, Niterói, v. 20, n. 33, jan./jun. 2019. 
Ainda assim, observa-se o questionamento do sentido de fenômeno artístico e humano em escavações de si mesmo como necessidade e condição vital de outramentos, que vêm impulsionando a investigação d@s artistas, pesquisador@s e curador@s aqui presentes, desde Analu Cunha, Keyna Elielson, Suzana Queiroga e radicalmente, Ernesto Neto, Jorge Barco e Guilherme Vaz. O confronto com fronteiras multissensoriais em estranhamentos de si mesmos acompanhando colapsos civilizatórios; o reconhecimento do estranho e do comum, das selvas e silvas, ruínas urbanas traduzidas por enunciações de quebras do antropocentrismo; visões da convivialidade entre os diferentes reinos e organismos vivos (minerais, vegetais e animais). Estes movimentos definem intuições palpáveis, comunhões e dádivas (Vaz), acompanhando as ressonâncias do incendiar de Hoff com as desformas do primado do olho ("que atrapalha") ou do ego do artista (Vaz) contra o qual Guilherme Vaz, assim como Ernesto Neto e as novas gerações, estão tecendo novos fios sensoriais e éticos de mobilizações de estados ampliados de escuta e de consciência. "Isso é" devir floresta (parafraseando "isso é contrapedagogia" de Monica Hoff). O desconforto se torna potência de reconfiguração do papel e da pertinência da arte e da educação radical como agentes de novas conectividades éticas, estéticos e políticas - "isso é" devir floresta.

O devir de uma filosofia da prática do pensar-agir floresta está presente como um emaranhamento "incivilizatório" na diversidade vital de dobraduras de imaginários pragmáticos instituintes de transbordas marginais do "desaprender e incendiar" em linhas de irradiação centrífuga-centrípeta de reversibilidades dos avessos dentro-fora do corpo de múltiplos corpos, de multissensorialidades como centralidade da produção de conhecimento decolonial.

O outramento humano é também da instituição escola que se realiza como práticas experimentais colaborativas, tal como Bárbara Szaniecki, Lívia Flores, Michelle Sommer, Soledad García Saavedra e Evanthia Tselika propõem para uma ecologia da experiência do "comum". A interdependência da formação e educação do artista também se desloca tanto para as escavações de si, em produção de novas subjetividades, quanto para novas cosmogonias, tanto para a vida comum quanto para as ações coletivas-colaborativas e 
movimentos sociais. Nesta cartografia encarnada em polifonias e sinergias, os posicionamentos éticos apontam para a própria quebra de uma "arrogância homogênica" (MANATA, 2016, p. 265) dos resíduos de uma ilusão ocidental de centralidade autoral da criação. Nas próprias trajetórias de Helio Oiticica e Lygia Clark já estavam sendo reconfigurados os estados de "descoberta e invenção" (referência a Oiticica) compartilhados, como "Devolver a Terra a Terra" ou a "Nostalgia do Corpo". O devir floresta acompanha a trajetória de vários grandes artistas que atingiram um grau de viradas estéticas da antiarte, cuja a culminância aponta para deslocamentos éticos, como Oiticica em propor proposições, ou Vaz em sua homenagem ao silêncio, as escutas do universo em torno incluindo os reinos animais, vegetais e minerais. "Os seres denominados árvores detêm um tipo de conhecimento desconhecido para o homem", ampliam o sentido de participação colaborativa na cocriação com a sociedade.

Tal como novas tendências ou zeitgeist, o impulso aos deslitígios também estão presentes nas fugas das escolas gaiolas para as asas das bordas, para as margens e mangues, onde as linhas orgânicas institucionais e instituintes retomam as marchas inacabadas das antropofagias. Assim Barbara Szaniecki aponta e relembra que "só me interessa o que não é meu". Porém, assume o pragmatismo utópico como plataforma de trocas e necessidades vitais. Szaniecki, Lívia Flores, Michelle Sommer, como também Evanthia Tselika (Universidade de Nicósia), convergem esforços para um eixo comum de ações nômades, extramuros rompendo as utopias de isolamentos das ilhas, ou universidades, do Chipre ao Fundão. As práticas colaborativas distinguem uma nova virada da arte pública, por um desaprender solidário por emaranhamentos incivilizatórios das universidades, bem definido, ainda por Barbara Szaniecki como "design-devir com outros". Os delírios itinerantes da Lygia Pape e Oiticica são reconfigurados para o desaprender solidário proposto por Evanthia no encontro entre estudantes de arte com refugiados atuando em re-assentamentos habitacionais em Nicosia; ou ainda, como no projeto Desilhas, apresentado aqui por Lívia Flores e Michele Sommer, como movimento em direção à escuta do entorno e dos ruídos ao redor (UFRJ) . "A curva é social" ecoa a voz do Guilherme Vaz.

Poiésis, Niterói, v. 20, n. 33, jan./jun. 2019. 


\section{Correndo para a Savana}

\section{Oque nós queremos dizer é que uma árvore é uma civilização.}

-- Guilherme Vaz (2017a, p. 264)

A origem das habilidades extraordinárias

[...] para a construção da era não moderna.

[...] Ao povo comum - antes das coisas virarem arte ou um cesto de palha, antes das coisas virarem coisas das quais todo mundo fala, existe o mundo do sonho que é a vontade pura. 0 pilão antes do pilão. A renda antes da renda. 0 cesto antes do cesto. A borduna antes da borduna. A mó antes da mó. Assim foi feito - antes de ser feito. [...]

Aos artistas - antes da arte existe o mundo da paleoarte, da paleofania e da paleossonia [...] Existetam-bém a paleosselva. Antes.

-- GuilhermeVaz (2017a, p. 260)

O pensamento floresta de Dion Workman, traduzido por Jorge Menna Barreto, expressa bem esses deslocamentos do devir-floresta. O regime mono-focal estético de primado da visualidade dá lugar ao sentido ético de escuta ampliada do lugar - "O comportamento inversionista provocou ricas reflexões e foi responsável por um belo texto que discorre sobre a escuta do lugar, renúncia, novos modos de estar no mundo, anarquia, diversidade..." $O$ interesse experimental-floresta se abre para saberes das margens ou de deslocamentos para outras múltiplas centralidades que podem também ser revistas como processos geopoéticos, de acordo com sinergias da "permacultura feral" de Workman como

[...] um sistema para projetar "incivilização": As chamadas "estruturas invisíveis" da permacultura - as estruturas sociais, econômicas e jurídicas das sociedades humanas, as quais podem também ser chamadas de gaiolas da civilização - devem se tornar visíveis, abertas e submetidas a intenso escrutínio. ${ }^{5}$ 
Os museus e as escolas de arte igualmente vêm sendo diretamente atingidos por esse devir floresta ou deslocamentos e quebras que podem ser associados a uma reação sistêmica ou endêmica contra o capitalismo que se reflete no articentrismo (ACHA, 1979) ${ }^{6}$ ou antropocentrismo. Juan Acha, rechaçando o eurocentrismo, ajuda a pensar sobre escolas de arte não como um sistema único de valores subalternos ao articentrismo, monoesteticismo e bello-manias (manias de belo). Seu posicionamento decolonial vai contra a um único conceito de arte ou de beleza; neste sentido, é também floresta tropical, vegetação emaranhada de diversidades de fauna e flora, como negação de um princípio estético exclusivo e único - (mono-esteticismo) - com bases e raízes ocidentais.

O devir floresta também está presente nos processos de desfazimentos institucionais, quebras epistêmicas ${ }^{7}$ ligadas à instabilidade de um sistema universal conduzido pelo primado antropocêntrico espelhado essencialmente no eurocentrismo indissociável da exploração global capitalista de povos colonizados/subalternos e, por extensão, os recursos naturais de suas terras, águas e florestas. Este ponto de inflexão para a floresta se encontra ativo em várias obras e ideias deixadas por Guilherme Vaz: o homem correndo na savana; o deslitígio do universo; nós somos o coiote, que encapsulam uma síntese de sua criação como "fração do infinito". Vaz incorpora o devir presente de floresta tanto em sua concepção musical quanto filosófica de leitura de mundo.

\section{Estamos dizendo e afirmando que existem sinais de escrita entre os animais e que os seres denominados "árvores" detém um tipo de conhecimento desconhecido para o homem. Estamos dizendo em todos os sentidos que todos os seres vivos possuem linguagem e mesmo os minerais a possuem. (VAZ, 2017b, p. 265)}

Talvez seja justamente pelos fundamentos da arte em seu princípio e espírito de floresta e liberdade que as escolas públicas no Brasil estejam diante o enfrentamento de uma política de ataque diretamente contra a presença em seus currículos das disciplinas que formam asas para o pensamento livre, ao que não se conforma a redução funcionalista da educação ou da condição e destino humano.

Poiésis, Niterói, v. 20, n. 33, jan./jun. 2019. 
E daí também que esse dossiê reúne $360^{\circ}$ de abordagens formando linhas de emaranhamentos e atravessamentos de resistências decoloniais (geo)poéticas, de posicionamentos éticos, político-pedagógicos e ações ambientais com bases colaborativas para prospectar linhas orgânicas em jogo nos imaginários instituintes (CASTORIADIS, 1994, p. 2) de liberdade experimental ampliada para escolas floresta de arte pública. Devir floresta é tanto geopoético quanto micropolítico, não como romantismo do civilizado na sua mirada para a selva, mas como uma ecologia da conectividade de consciências expandidas para áreas do inconsciente (Vaz), capaz de adotar uma "contrapedagogia" instituinte que traduza o que Castoriadis propõe como "devir autônomo do sujeito em sentido duplo como libertação de sua imaginação e a instauração reflexionante e deliberante que dialogue com essa imaginação e julgue seus produtos." Ou como Guattari responde a um "mundo que se deteriora" através da unidade de três ecologias - ou ecosofia - "em desenvolver práticas específicas que tendam a modificar e a reinventar maneiras de ser no seio do casal, da família, do contexto urbano, do trabalho etc." (GUATTARI, 1990)

É preciso também uma filosofia para esta escola de devires floresta - ou de uma escola de arte como "paralaboratório e instrumento de síntese", remontando a Mario Pedrosa (ARANTES, 1995) - que seja escrita por múltiplas vozes, mas que mantenha a polifonia das diferenças em conexões interdependentes. Esta perspectiva invoca o acontecimento e a formação de corporiedades para um outro sentido de síntese ética-estética-política, pois que está completamente atravessada pelas questões da subjetividade e da diversidade no engajamento experimental em zonas de contato, conflitos e singularidades. "O lugar da arte é o do acontecimento da conectividade que dá sentido à existência, retornando ao mundo um novo mundo quando está conectado." (Vaz)

Neste escola de arte pública, que se alinha também com as prospecções de Luiz Sérgio de Oliveira, emergem novas premissas para a formação e educação do/a artista junto - indissociável - das questões do "racismo, do falocentrismo, dos desastres legados por um urbanismo que se queria moderno, de uma criação artística libertada do sistema de mercado, de uma pedagogia capaz de inventar seus mediadores sociais etc." (GUATTARI, 1990) 
Este emaranhamento "incivilizatório" de Workman faz ressonância aos estados de "descoberta e invenção", "devolver a terra a terra" de Oiticica, conectados por esta cartografia de experiências artísticas. As reinvenções - outramentos das escolas de arte - encontram antecipações e inacabamentos perfeitamente apresentados por Rafael Zacca como microgeografias de futuros através de colapsos. Da Savana à Savana, do bólide ao contrabólide, da pedagogia à contra-pedagogia, da antropologia à antropofagia, do civilizatório ao incivilizatório, assim também Oiticica reencontra Oiticica. O CONTRA-BÓLIDE "DEVOLVER A TERRA A TERRA" (Caju, 1979; OITICICA, 1996, p. 202) pode ser também uma escola de arte conectando o "aprender e incendiar" de Hoff com a "contra operação poética", a pedagogia um programa-obra in progress; a repetição, a intuição de um caráter ritualístico da gênese da arte. A floresta, a escola da margem, que investe em outramentos do centralizar-comunidades de modos de saberes que inauguram "conexões improváveis", tal como a "concreção de obra-gênese" de Oiticica pelo repetir a "invençãodescoberta" do Bólide (1963).

A "curva é social", a missão capital da arte é a margem alimentando conexões improváveis, já manifestando visões e especulações sobre "quebras do antropocentrismo", "deslitígios do universo" que reconhecem nas "árvores civilizações" e nas florestas um cosmo produtor de outras enunciações e linguagens além da razão humana. É possível reconhecer ainda afinidades filosóficas entre Vaz, Nietzsche e Graça Aranha nos pontos capitais da missão da arte, na "intuição que precede a comunhão e, daí, a dádiva" - de "retornar ao mundo um novo mundo". A complexidade em jogo para uma escola de arte em tempos de retrocessos fortalece o impulso intuitivo de Vaz para seu devir comunhão floresta e dádiva - como um princípio nietzschiano de "retornar ao mundo a invenção de um novo mundo" - repetido como mantra em sua entrevista. O pensar e agir direto das ruínas das certezas civilizatórias repudia as bases conservadoras de um monoesteticismo. "Isso é contrapedagogia"! (parafraseando o manifesto da Mônica Hoff). É preciso cruzar ações e reflexões articuladas por "conexões improváveis" (Vaz) nas diferentes narrativas aqui reunidas.

Poiésis, Niterói, v. 20, n. 33, jan./jun. 2019. 
Suzana Queiroga em trânsito entre Portugal e Brasil (2018-2019) justapõe visões aéreas com rupturas e quebras ao rés do chão, dos pavimentos que cobriram o barro, a savana e a alegria da floresta. Mesmo assim, Suzana ainda busca por novas cartografias sobrevoando, com o motor binário "descoberta-invenção" de Oiticica, as malhas urbanas como extensões de si, que reconhece nos cruzamentos entre ruas a epiderme do mundo indissociável da condição humana. A complexidade do fracasso do projeto modernista das cidades não está fora de nós, nem a dimensão subcutânea da "espessura do presente" (citando Mario Pedrosa).

Se as raízes construtivistas geraram vanguardas revolucionárias no início do século $\mathrm{XX}$, também uniram o cotidiano com a festa, o ritmo do jazz com as malhas da grande Broadway Boogie Woogie (1942-43) de Piet Mondrian. Inaugurava-se um modo de vida mecânico com brechas anacrônicas para a alegria imanente ao delírio sublime de Mondrian. A horizontalidade topológica da geometria funcionalista das cidades e prédios máquinas (também máquinas estéticas) e suas perspectivas de pranchetas em favor do sucesso pela ordem e progresso da velocidade urbana para o crescimento infinito dos movimentos das grandes massas humanas. O ensaio visual de Suzana trata da falência dessa visão de controle e ordem das geometrias das cidades, das diferentes redes de trânsitos e labirintos planejados, quando as brechas abrem do chão uma demanda universal de "devolver a terra a terra".

O que se tem agora é uma contra-estética de colapsos e empilhamentos ou, paradoxalmente, um desconstrutivismo psico-sócio-espiritual que rejeita o primado de 500 anos da "perspectiva" como instrumento panóptico de projeção e controle que possa reger não apenas a representação na pintura, mas os deslocamentos do ir e vir cotidiano-urbano. $\mathrm{O}$ emaranhamento e desforma dessas geometrias urbanas materializam os imaginários de Suzana como acúmulos acidentais, um cubismo onde a fragmentação não é apenas do sujeito, mas das incertezas e estados de inquietudes existenciais, de ser parte molecular também de processos globais de entropias e novas conexões ainda improváveis. O fim de mundos ou de utopias progressistas é também o prenúncio de ruínas dos regimes das perspectivas, do controle projetivo civilizatório pelo capital. A criação artística assume o 
lugar de exercícios de intuições existenciais e comunhões geopoéticas de "seus habitantes e da natureza investindo na construção de uma nova cartografia." Suzana expõe através de rachaduras um mosaico inacabado de desfazimentos "por uma alteração na topologia do tecido urbano" que, ainda assim, encontra resistência para indagar - pode "a arte criar um novo ponto no mapa cognitivo?"

Analu Cunha, por sua vez, explora uma outra fronteira de si através de Silvas, Silvios, Silvanas. Diante das perplexidades complexas que nos cercam, como pensar a emergência dessa selva (mal) recalcada (?), a partir de uma certa escavação semântica que se desdobra entre Silvas e Selvas. A ideia de floresta cruza a exposição Selva reunindo duas vídeo-instalações da Analu com os trabalhos da Carla Guagliardi, João Modé e Rochelle Costi, provocando diferentes "descobrimentos e invenções" (remetendo a Oiticica) de obras gêneses de brasis profundos de nós mesmos. Onde se percebe, através do texto de Analu, a experiência de ser estrangeira, desterrados e estranhos brasileiros e brasileiras entre dois mundos, da arte e das outras bordas e fronteiras do Brasil.

Não existe arte sem ressonância. A intuição é parte de um estado paradoxal de comunhão com um contexto que junta coisas aparentemente improváveis de se conectarem.

O estado de comunhão é uma dádiva ou dom de uma metafísica da arte. Unir signos díspares.

A experiência do estado de comunhão paradoxalmente dá sentido à existência, ao que ainda não tem lugar na consciência do mundo.

-. GuilhermeVaz

Habitar outras fronteiras, compartilhar outras formas de viver, rituais, medicina, espiritualidade e filosofia como unidade de potência fundamental vem alimentando e transformando radicalmente a trajetória dessas prospecções artísticas. Ernesto Neto, igualmente, reconhece o fracasso do mundo do "cheio" a partir de seu contato e imersão com

Poiésis, Niterói, v. 20, n. 33, jan./jun. 2019. 
a sabedoria dos huni kuin. Faz contato com uma outra ordem de sentidos de estar no mundo através da vivência de cantos, rituais e danças onde todos participam reconstruindo uma unidade perdida na arte e na razão ocidental. Com as experiências do Neto pode-se reconfigurar uma reversão de ordens entre civilização ocidental e outras "incivilizatórias" como revoluções e outramentos metafísicos a partir de colapsos. O próprio artista chama de "universidade da floresta" o mergulho ao centro de si mesmo, como um estudo de um infinito interior. Nesse outramento, Neto percebe a questão do "olho". O aspecto visual não é mais tão valorizado como percebe na convivência com os povos da floresta. A partir das experiências diretas em seus rituais, Neto reconhece nas aldeias indígenas a transcendência e imanência de outras sensibilidades além da visão. Quando a noite chega, com o escurecer na floresta, acendem-se as fogueiras e as rezas, danças e cantorias indígenas dão início a rodas de inflexões cósmicas e metafísicas. Ao se ver menos, os outros sentidos se tornam mais expandidos, ampliando a vivência de incorporações de unidades imanentes e transcendentes de múltiplos corpos e vozes. Então ele percebe - "o olho atrapalha". Lembrando Eduardo Viveiro de Castro - na cultura ocidental é preciso de objetividade, do "triunfo do olhar" para se chegar à verdade. Nas culturas não ocidentais, os outros sentidos integram um especial foco em outras formas de visões, sonhos e transformações que ultrapassam a ilusão de valores civilizatórios que ainda regem a sociedade contemporâneo. Nestas imersões na escola da floresta, Neto reflete toda a trajetória da arte ocidental através do primado do olhar (triunfo do olhar ou o olho atrapalha). O que constantemente relembra o manifesto da Mônica Hoff - como "desaprender e incendiar" para que se dê lugar aos imaginários instituintes da uma outra escola de asas onde a convivialidade emerge como criação e alegria coletiva - interdependente.

\section{0 espírito recusa-se a conceber 0 espírito sem o corpo. 0 antropomorfismo. Necessidade da vacina antro- pofágica. Para o equilíbrio contra as religiões de meridiana. E as inquisições exteriores. (ANDRADE, 1990, p. 48)}

Nesta reversibilidade causal, tanto Ernesto Neto, Jorge Barco quanto Vaz revivem "a metafísica bárbara" (NUNES, 1990, p. 23), a vacina antropofágica de Andrade, mas ampliada 
para um sentido de materialidade espiritual como devir indissociável do autoconhecimento especialmente dos brasileiros, filhos de mãe índia, mãe africana. Por diferentes trajetórias, esta escola está sendo intuída por comunhões e dádivas (enunciadas por Vaz) em seu devir floresta para encontrar um outro caminho além do primado do olhar. Barco, Neto e Vaz investem em outramentos antropofágicos entre arte, comunhão e xamanismo, de acordo com a definição de Els Lagrou, antropóloga e professora da UFRJ. (LAGROU, 2019, p. 111)

É possível, respeitando as devidas singularidades, aproximar em especial a obra de Neto e Barco pela busca da multissensorialidade e espiritualidade, assumindo a concepção de ambientes que radicalizam o sentido público da arte como espaço de convivialidade e de reencantamento. Neto, em especial, vem radicalizando suas intervenções e invenções públicas atraindo todas as idades. Seu posicionamento político dá legitimidade ética-estética para a alegria pela total imersão e acolhimento de uma outra sabedoria de vida fora da razão ocidental, com base na escola-floresta de rituais do povo huni kuin, no Acre.

Neto recupera um sentido de alegria que vai além de Oswald de Andrade na prova dos nove de seu manifesto antropofágico. Aflora aí uma intuição vivencial no convívio com os povos da floresta do que Graça Aranha explora como uma "alegria cósmica", assim citada por Benedito Nunes. Na "esthética da vida" de Graça Aranha (1921) se encontra um profundo sentido de alegria espinosiana como força cósmica:

\section{Ao passo que no conceito do Universo, como unidade infrangivel de toda a natureza, a vida dos seres seria a da perpétua alegria pela eliminação do terror metaphysico. (ARANHA, 1921)}

É possível resgatar as incertezas da "metaphysica" de Graça Aranha de 1921 para os dias de hoje como um devir inacabado de um visionário diante da tristeza dos brasileiros desterrados europeus e a abundância estranha da floresta. Ainda estão presentes fortes ressonâncias entre as falas do Neto, Barco e Vaz com as indagações sobre uma filosofia da ação e da unidade com um Todo infinito proposto por Aranha.

Poiésis, Niterói, v. 20, n. 33, jan./jun. 2019. 
A Esthetica da Vida proclama que só pela actividade o espirito se pôde tornar um com o Universo, extinguir todas as separações e fundir-se esplendidamente no Todo infinito. As três grandes disciplinas em que se baseia a ethica desta esthetica da vida são: 1‥ A resignação à fatalidade cósmica; 2ํ. A incorporação à terra; 3‥ A ligação com os outros homens. São esses os trabalhos morais do homem dentro das categorias em que fatalmente têm de existir, Universo, Terra, Sociedade. (ARANHA, 1921, p. 27)

Chega-se às relações entre Oswald de Andrade e Aranha na enigmática conclusão do Manifesto Antropofágico - "a alegria é a prova dos nove". Pois que Aranha aprofunda suas inquisições éticas e filosóficas em Espinosa, onde a unidade a um Todo infinito implica em um pertencimento e ação imanente como também a um sentido cósmico de alegria.

\section{Mas a concepção de Spinoza se alarga, quando procura conciliar o egoísmo do ser com a sympathia universal entre todos os seres. "Os homens, diz elle, nada podem desejar de melhor, para a conservação do próprio ser, que esse amor de todos em todas as cousas, que faz com que todas as almas e todos os corpos formem por assim dizer uma só alma e um só corpo..." (ARANHA, 1921, p. 24)}

Ainda com a proposição de Guilherme Vaz para uma "fração do infinito" reencontram-se ecos da Ética de Espinosa através de Graça Aranha. Esta cartografia do Brasil, antropofagia e floresta, é igualmente infinita. Espinosa chega ao Brasil através de uma indagação do Aranha que cruza múltiplas transtemporalidades, panteísta, imanente e de unidade através de "frações do infinito" - onde, como nossos povos originais na escola da floresta, celebram também que "todos os corpos formem por assim dizer uma só alma e um só corpo...

Não há dúvida que Spinoza se approximou mais que ninguém da concepção essencial da Unidade infinita dos seres, quando affirmou que o homem é uma ínfima parte da natureza eterna. (ARANHA, 1921. p. 25)

\section{Ancestralidade da arte contemporânea - outros anacronismos utópicos}

Com a entrevista com Keyna Eleison traz-se aqui, igualmente, uma outra geração que escava a si mesma como parte do emaranhamento das raízes brasileiras que aponta para uma arqueologia de devires ancestrais desterrados, diásporas presentes que cantam, 
através de sua própria biografia, os outros saberes não ainda completamente conscientes. Na palavra §.\$ंC. - Fik'ri. (amor em amárico), Keyna resgata, a partir de empatias e intuições ressonâncias imemoriais, como uma outra camada emergente em processo nas práticas e motivações para se pensar curadoria, escola de arte, que não remetem especificamente às delimitações das razões ocidentais. A ancestralidade afro-brasileira, que não se enquadrava ou foi reprimida na formação cultural brasileira, torna-se uma outra fronteira-floresta de viradas para a produção de conhecimento que rompe com os cânones e padrões dessa mesma razão monoesteticista visual.

Explora-se aqui o pensamento floresta como se fosse uma rede de ressonâncias do inconsciente antropofágico de um outro espírito de resistência e utopias ao avesso, ao rés do chão, mas, ainda que flutuante, resiste a qualquer determinismo estabilizador de categorias de juízo ou de análise. O que implica tanto para os processos artísticos quanto suas institucionalidades em escolas ou museus, em escritas encarnadas sobre a ação reflexiva que se inscreve em acompanhamento-intervenção cartográfica (PASSOS; KASTRUP; ESCÓSSIA, 2009) no mundo. Assim, também as "Desilha: Derivas Acadêmicas" de Lívia Flores e Michelle Sommer abrem sobre a própria universidade uma contundente extensão e imersão para fora de suas paredes, movidas pelo espírito de utopia antropofágica para uma outra ação de desejos de pesquisa-intervenção. Desilhas e Derivas combinam plataformas de ação e reflexão experimental de buscas por novas conectividades geopoéticas na trans-borda, floresta, do avesso do projeto acadêmico instituído na fundação da Universidade do Rio de Janeiro.

Assim, observa-se, nos diferentes artigos-narrativas, o testemunho ativo de esforços de desformas por linhas de transformações das instituições em "conceptáculos", institucionalidades em estado instituinte de contínuas reinvenções ou "casa de experimentos" (Pedrosa abordado em texto da Soledad). O pensamento experimental, floresta, se torna força motriz e estratégia, tal como Barbara Szaniecki compartilha em sua própria microutopia cruzando os "emaranhamentos universidade-sociedade", por uma constituição política engajada de design coletivo, colaborativo em "campo e entre campos na cidade no Laboratório de Design e Antropologia da ESDI/UERJ."

Poiésis, Niterói, v. 20, n. 33, jan./jun. 2019. 
O "outramento" elaborado por Pelbart (2004/2011) é também reconfigurado por Barbara como "design-devir com outros". Ao mesmo tempo, a autora-propositora resgata a Antropofagia de Oswald de Andrade por sua corporiedade-estômago. Estes relatos exploram uma possibilidade de síntese da "arte-ciência nômade inspirada em Deleuze e Guattari", mas que poderia ser expressa em seu avesso como Guilherme Vaz apresenta - arte antes de ser arte, ciência antes de ser ciência. O experimental e o devir floresta podem ser vistos como terapêuticas institucionais (GUATTARI, 1985, p. 88) antropofágicas que invocam também a "necessidade vital da arte" de Mário Pedrosa em sua ativação e conectividade entre imaginários instituintes improváveis. Somente através de estados de desobediência e de libertação epistêmica decolonial, este devir floresta com outros incorpora para si o outramento ativo do futuro (não-ainda de Bloch), do front que habita a adversidade e espessura do presente (Pedrosa) $)^{8}$ e o Novum imediato nos impulsos de resistir, insistir, por linhas de fuga, microgeografias de afetos alegres espinosianos. "A alegria é a prova dos nove"r9.

A reversibilidade Escola-Floresta-Escola impulsiona tanto os movimentos de desterritorialização quanto reterritorialização (Deleuze e Guattari) institucional. Ainda, a transborda se realiza como atravessamentos que reversamente gera uma filosofia de ações nômades como formas de resistência e re-existência da escola de arte, como no caso do projeto Desilhas de Lívia Flores e Michelle Sommer. Ou também no design-devir com o outro do que faz da relação universidade-sociedade um laboratório social de colaborações proposto Barbara Szaniecki. Assim, também Evanthia Tselika, com os estudantes do curso de Belas Artes da Universidade de Nicósia, gera um deslocamento radical do "ateliê-sala de aula" para um bairro de assentamentos de refugiados moradores de conjuntos habitacionais em colaboração com a Artos Foundation.

Observa-se, em todos esses casos, o quanto o acontecer solidário de Milton Santos (2002, p. 165-167) dentro de uma escala de microgeografias de afeto está implícito na dobradura ética contemporânea da arte pública invocando uma outra formação-educação de artistas com um posicionamento público deslocado de sua própria centralidade articentrista para atuarem, como cocriadores de diálogos, tal como a experiência com os mora- 
dores de Strovolos III com os estudantes moldam uma série de mapeamentos de questões e ações criativas.

Assim, também Soledad García Saavedra ${ }^{10}$ investe no resgate das raízes do Museo de la Solidaridad Salvador Allende através de um programa integrado de curadoria e de mediação cultural voltado a uma "Mirada de Barrio", devolvendo a solidariedade à vida do museu, à sociedade, atualizando e expandindo os conceitos de Para-laboratório e Casa de experimentos de Mario Pedrosa. O Museu é reinventado não pelo poder de uma narrativa hegemônica de uma coleção, mas como agente de solidariedade, integrando os saberes da comunidade vizinha ao programa de ressignificação e reconfiguração curatorial participativa.

Como conectar as trajetórias das obras e exposições com as experiências e conhecimentos das pessoas? Como gerar uma proximidade do museu com o seu entorno e, daí, um sentido de pertencimento na vida dos habitantes de um "bairro" (porcón) da cidade de Santiago? ${ }^{11}$

Soledad aposta em uma institucionalidade experimental da curadoria e mediação refletida como "casa de experimentos", a partir da quebra dos valores modernistas de uma razão determinante sobre outras razões, ao mesmo tempo que investe na indeterminância dos processos afetivos envolvendo "a flexibilização museal"12, a participação e produção de processos de subjetivação e acolhimento de outros saberes. Museu-Escola-Floresta são integrados por Soledad como amplitude e atualidade do que Mario Pedrosa articulou como "paralaboratório". (FERREIRA; HERKENHOFF, 2015, p. 142)

Desta coleta de vozes do moderno ao contemporâneo, rastreiam-se as marchas das utopias inacabadas, como palimpsesto da adversidade que forma um devir anacrônico de escola-floresta Brasil. Uma cartografia cognitiva das polifonias das margens indaga pelo que pode porvir de suas potências frágeis e imateriais, da "necessidade vital da arte" de Graça Aranha a Mario Pedrosa, o que "deveria proteger o seu ori, seu chakra debaixo do sol"? (BORGES, 2019)

Poiésis, Niterói, v. 20, n. 33, jan./jun. 2019. 
Uma filosofia floresta se propõe como prospeç̧ão e reconfiguração de valores que realimentam o fenômeno humano tão ameaçado pela globalização capitalista em jogo. Por isso, aqui reúnem-se colaborações nacionais e internacionais que compõem ações e interlocuções essencialmente de contrafluxos e deslocamentos das centralidades afirmadas por narrativas instituídas hegemônicas. O que se percebe, na mesma medida deste desmonte do bem comum da esfera pública, é a emergência de linhas de forças de resistência e ressonâncias transculturais e transmodernas compondo uma rede de práticas decoloniais de desobediências e estados de "descoberta-invenção" de novas redes de conectividades de saberes intuitivos - experimentais. Daí, floresta tem também o sentido de "não ainda consciente", como Ernst Bloch (2005) propõe como "função utópica da arte" de antecipar futuros não concluídos, ou conectividades ainda improváveis (como missão da arte para Vaz) - entre as artes, a educação e as outras ciências. Invoca-se aqui uma inflexão contínua para a floresta/escola/floresta como "tática adversa" da potência frágil de agir da arte através de microgeografias de afetos, produção de possíveis comunidades, comunhão e dádivas sociais. 


\section{Notas}

${ }^{1}$ Conversas entre Guilherme Vaz e Luiz Guilherme Vergara gravadas em vídeo por Daniel Leão, durante a exposição Fração do Infinito. Rio de Janeiro, CCBB, 2017.

${ }^{2}$ Especulações estéticas III. Lance Final. Correio da Manhã. Rio de Janeiro, 9 de abril de1967 (in AMARAL, 2007, e in ARANTES, 1995).

${ }^{3}$ Leitura emprestada de um encontro na barca Rio-Niterói, dia 28 de junho de 2019, com Cleiton Santos, que me apresentou o livro de Stephanie Borges, Talvez precisemos de um nome para isso (Recife, Ed. Cepe, 2019), livro vencedor na categoria Poesia do $4^{\circ}$ Prêmio CEPE Nacional de Literatura no ano de 2018. (CEPE - Companhia Editora de Pernambuco)

${ }^{4}$ A ideia de inacabamento seguiria com Freire até o final de sua vida, como vemos na Pedagogia da autonomia (1996, p. 50-52).

${ }^{5}$ Apresentação de Barreto para Dion Workman. Uma Introdução ao pensar como uma floresta. Tradução de Jorge Menna Barreto. Texto original em inglês publicado em shikigami.net/Forest/introduction-thinking-like-forest. Acesso em 19/7/2015.

${ }^{6}$ Juan Acha. "En tal sentido, su punto de partida implica un rechazo de lo que él denomina: eurocentrismos, articentrismos, monoesteticismos y bello-manías. Es decir, rechazo de toda estética que se construya desde categorías europeas exclusiva-mente (eurocentrismo), de toda reflexión que se centre en un único y excluyente concepto de arte o de belleza, generalmente occidental (articentrismo y bello-manía), o que pretenda la existencia de un exclusivo principio estético (monoesteticismo). In Vicente, Sonia. Tiempos de diseño. Una vision de la teoria de los diseños desde la postura de Juan Acha. Módulo 1: Mendoza: Módulo I. Universidad y Sociedad. Facultad de Artes y Diseño, 2000. Ingresso 2001. Ver também: ACHA, Juan. Arte y Sociedade: Latinoamérica. El sistema de produción. México: Fondo de Cultura Económica, 1979.

7 Dentro da produção crítica decolonial Ramon Grosfoguel, Aimé Césaire, Enrique Dussel, Walter Mignolo e Katherine Walsh defendem uma virada epistêmica abrangendo as instituições produtoras de pensamento e pedagogias que possam atingir os modos de percepção e posicionamento perante as estruturas sociais e políticas. Leitura recomendada. GROSFOGUEL, Ramon. Para um pluri-versalismo transmoderno. Tabula Rasa, Bogotá, n.9, p. 199-215, jul.-ago. 2008.

${ }^{8}$ Mario Pedrosa. Especulações estéticas III. Lance Final.

${ }^{9}$ ANDRADE, Oswald de. Poesia Pau-Brasil. Correio da Manhã, 18 de março de 1924.

${ }^{10}$ Historiadora del arte (Universidad de Chile), curadora (Goldsmiths College, Univeristy of London). Coordinadora Programas públicos, Museo de la Solidaridad Salvador Allende, Santiago de Chile.

11 Tradução livre do original em espanhol: “¿cómo conectar las trayectorias de las obras y exposiciones con las experiencias y conocimientos de las personas?, ¿cómo generar una cercanía del museo con su entorno y un sentido de pertenencia en la vida de los habitantes en una porción de la ciudad de Santiago?

12 flexibilizar las estructuras museales.

Poiésis, Niterói, v. 20, n. 33, jan./jun. 2019. 


\section{Referências}

ALVES, Rubem. Há escolas que são gaiolas. Há escolas que são asas. In ALVES, Rubem. Gaiolas ou Asas? Revista Educação. Disponível em https://www.revistaeducacao.com.br/ gaiolas-ou-asas/

AMARAL, Aracy. Mundo, homem, arte em crise. São Paulo: Perspectiva, 2007.

ARANHA, Graça. A esthetica da vida. Rio de Janeiro: Livraria Garnier, 1921.

ARANTES, Otília (Org.). Forma e percepção estética. Mário Pedrosa. Textos escolhidos II. São Paulo: Edusp, 1995.

ANDRADE, Oswald de. Poesia Pau-Brasil. In ANDRADE, Oswald de. A utopia antropofágica. São Paulo: Globo, 1990.

BLOCH, Ernst. O Princípio Esperança. Rio de Janeiro: Contraponto; Ed. UERJ, 2005.

BORGES, Stephanie. Talvez precisemos de um nome para isso. Recife: Ed. Cepe, 2019.

CASTORIADIS, Cornelius. Tiempo e Imaginacion. Zona Erógena, n. 18, 1994.

FERREIRA, Gloria; HeRKenHOfF, Paulo. Mário Pedrosa Primary Documents. Nova York: The Museum of Modern Art, 2015.

GUATTARI, Félix. Revolução molecular: pulsações políticas do desejo. São Paulo: Brasiliense, 1985.

GUATTARI, Felix. As três ecologias. São Paulo: Papirus Editora, 1990.

LAGROU, Els. No ventre do monstro: Leviathan, Yube e Neto. In VOLZ, Jochen; PICCOLI, Valéria. Ernesto Neto: Sopro (curadoria). São Paulo: Pinacoteca de São Paulo, 2019.

PASSOS, Eduardo; KASTRUP, Virginia; ESCÓSSIA, Liliana da (Org.). Pistas do método da cartografia. Pesquisa-intervenção e produção de subjetividade. Porto Alegre: Editora Sulina, 2009.

PEDROSA, Mario. Anacronismo de uma Utopia. In AMARAL, Aracy. Mario Pedrosa. Dos Murais de Portinari aos Espaços de Brasília. São Paulo: Perspectiva, 1981. 
PELBART, Peter Pal. O filósofo Gilles Deleuze, juntamente com Félix Guattari, batizou esse "tornar-se outro de devir." Revista Bordas, n. 0 (2004/2011). Disponível em https://revistas.pucsp.br/bordas/article/view/7734 .

OITICICA, Hélio. Catálogo Exposição Centro de Arte Helio Oiticica. Rio de Janeiro: Projeto Hélio Oiticica, 1996.

NUNES, Benedito. A metafisica bárbara e também localistae tribal: o sentimento órfico se regionaliza, e produz, segundo a terra em que vivemos, uma imagem de Deus. A Antropofagia ao alcance de todos. In ANDRADE, Oswald de. Utopia Antropofágica. São Paulo: Editora Globo, 1990.

SANTOS, Milton. O processo espacial: o acontecer solidário. In SANTOS, Milton. $A$ natureza do espaço. São Paulo: Edusp, 2002.

VAZ, Guilherme. O homem correndo na savanna? Anhanguera Paranaíba. In MANATA, Franz. Guilherme Vaz. Uma fração do infinito. Rio de Janeiro: Centro Cultural Banco do Brasil, 2017a.

VAZ, Guilherme. O deslitígio do universo. In MANATA, Franz. Guilherme Vaz. Uma fração do infinito. Rio de Janeiro: Centro Cultural Banco do Brasil, 2017. 